\title{
Trainings to train nursing teachers helping nursing students learn ethics: feedback of the
} participants

\author{
Piryani Rano Mal ${ }^{*}$, Piryani Suneel
}

$1_{\text {Professor and Head of Department of Internal Medicine and Chief Coordinator, Health Professions Training }}$ Committee, Universal College of Medical Sciences, Bhairahawa, Nepal

\author{
${ }^{2}$ Public Health Consultant, Karachi, Pakistan
}

\begin{abstract}
*Correspondence
Piryani Rano Mal,

Professor of Internal Medicine,

Universal College of Medical Sciences, Bhairahawa, Nepal.

E-mail: rano.piryani@gmail.com, r_piryani@hotmail.com

Orcid Id: 0000-0003-2574-7226
\end{abstract}

Head of Department of Internal Medicine, Chief Coordinator, Health Professions Training Committee,

Received: 16-06-2020 / Revised: 20-08-2020 / Accepted: 10-09-2020

\begin{abstract}
Introduction: Short-duration trainings for nursing faculty members in different contexts including ethics have been shown positive effect on faculty. The objective of the present study was to assess the feedback of the participant faculty members of "Trainings to train nursing teachers helping nursing students learn ethics." Methodology: The training of four credits hours to train nursing teachers helping nursing students learn ethics was organized in October 22, 2019 at Universal College of Medical Sciences, Bhairahawa Nepal. Fifteen nursing faculty members participated in the training. At the end of training feedback was taken from the participants using validated semi-structured questionnaire. Descriptive analysis was done using IBM SPSS version 21.Results: The rating of participants on

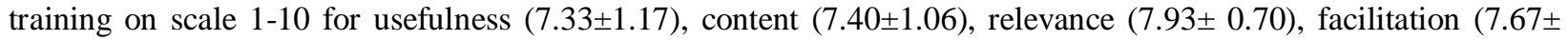
$0.98)$ and overall $(7.93 \pm 0.70)$ was notable. Their confidence level to conduct and facilitate "Think-Pair-Share" interactive session (3.68 \pm 0.69$)$ and "Scenario-based Group-Work Discussion" (3.76 \pm 0.83$)$ enhanced after training rated on Like rt scale $1-5(5=$ highly confident, $4=$ very confident, $3=$ confident, $2=$ to some extent confident $1=$ not confident). Participants rated session on "teaching clinical nursing ethics" an extremely important session (3.76 \pm 0.83$)$ on Like rt scale $1-4$ ( $4=$ extremely important, $3=$ moderately important, $2=$ slightly important, $1=$ not important). The participants mentioned that training environment was conducive and friendly, sessions were interactive and content was useful. They suggested to increase credit hours of training, conduct pre and post-test and include more scenario in curriculum of training. They committed for what was learnt will apply for teaching ethics to nursing students and in clinical nursing practice too. Conclusion: The rating of participants on the training was notable; the perception of participants was positive regarding training and training enhanced their confidence to teach ethics to students. This is obvious from their commitment.
\end{abstract}

Keywords: Ethics, feedback, nursing faculty, nursing students, short-duration training.

This is an Open Access article that uses a fund-ing model which does not charge readers or their institutions for access and distributed under the terms of the Creative Commons Attribution License (http://creativecommons.org/licenses/by/4.0) and the Budapest Open Access Initiative (http://www.budapestopenaccessinitiative.org/read), which permit unrestricted use, distribution, and reproduction in any medium, provided the original work is properly credited.

\section{Introduction}

Ethical issues, problems and dilemmas are experienced by all professionals; however, healthcare professionals are facing comparably more than others and are of complex nature. $[1,2]$
Nurses are among the largest group of healthcare providers in healthcare systems and have an immense impact on healthcare of population.[3] Due to technological revolution and increasing awareness, the number and complexity of ethical dilemmas have been increasing in clinical care settings, hence the promotion 
of professional values has become more critical in nursing education. The acquisition and internalization of ethical values are essential for fostering the nursing profession. [4, 5]

Besides knowledge and technical skills, nursing students and nurses must possess moral decisionmaking capacity and the ability to focus on the ethical aspects of patient care. [3, 6] Teaching ethics and professional values to nursing students enhance their capacity for autonomous ethical decision-making process. [4, 7]

Nursing educators, instructors, facilitators, teachers or faculty members are one of the important foundations of nursing education. They can increase nursing students' capacity and capabilities in various fields including ethics. [7] Nursing educators are real and effective role models, enhance creative learning of nursing students by encouraging their critical thinking and decision-making power and teach nursing students effective strategies to confront ethical dilemmas. [4, 7] Recognizing the role of nursing teachers in imparting ethics education to nursing students, Health Professional Training Committee of Universal College of Medical Sciences (UCMS) Bhairahawa Nepal organized "training to train nursing teachers helping nursing students learn ethics". The objective of this study was to take feedback of the participants and assess it.

\section{Methodology}

With the objectives to sensitize the nursing faculty members "why to teach ethics to nursing students" and prepare the nursing faculty members "helping nursing students learn nursing ethics"; "training to train nursing teachers helping nursing students learn ethics" was organized on October 22, 2019 by Health Professional Training Committee of Universal College of Medical Sciences (UCMS) Bhairahawa Nepal. The training was of 4 credit hours and the teaching learning methods used for training were tutorial and interactive teaching learning methods (brainstorming, think pair, and share session and scenario-based group work discussion).

Fifteen faculty members of college of nursing of UCMS participated in training. The principal author conducted the training as a resource person. The Theme of training was "Teaching Clinical Nursing Ethics- Why, What \& How".

There were three interactive session of training: "Think, Pair and Share", "Scenario-based Group Work Discussion" and "Teaching Clinical Nursing Ethics". The subject matter covered in session "Teaching Clinical Nursing Ethics" were: medicine in $21^{\text {st }}$ century, moral context of the nurse-patient relationship, professionalism, characteristics of nursing professions, teaching ethics and professionalism, principles of nursing ethics, teaching ethics-why, perspective of ethics education in nursing, goals of teaching nursing ethics, teaching ethic-what, role of instructor in teaching ethics, teaching nursing ethics in Nepal, Nursing pledge, International Council of Nursing (ICN) code of ethics for nursing, organization regulating nursing practice in Nepal, ethics policy of School of Nursing, Johns Hopkins University and ethics education for future generation of Nurses.

At the end of training feedback was taken from the participants on validated semi-structured questionnaire comprised of four parts: Part A. Demographic information, Part B. Overall feedback on training, Part C. Feedback on specific group of sessions and Part D. Feedback for improvement.

\section{Part A}

Demographic information: Info was taken from the participants on age in years, sex, year of graduation, teaching experience (teaching undergraduate and post graduate students) and whether received ethics related training before.

\section{Part B}

Overall feedback on training: This part contained one close ended question on rating workshop on scale 1-10 (1=poor, 10=excellent) for usefulness, content, relevance, facilitation and training as overall.

\section{Part C}

Feedback on specific sessions: This part covered three closed ended questions on specific sessions conducted in training. The questions second and third were on confidence level of participants rated at Like rt scale 14 (4= highly confident, $3=$ very confident, $2=$ confident, $1=$ not confident); the question second was "Are you confident to conduct and facilitate "Think, Pair and Share" interactive session for teaching nursing ethics to students?" and third was "Are you confident to conduct and facilitate "Group Work Discussion" session for teaching nursing ethics to students?". The fourth question was on importance of session "Teaching Clinical Nursing Ethics" rated at Like rt scale 1-4 (4=extremely important, 3=moderately important, 2=slightly important, $1=$ not important).

\section{Part D}

Feedback for areas of improvement, immediate impact and application in practice: This part had four open ended questions; question number fifth was on good points /strengths of training, sixth on "Areas for improvement", seventh on "Overall immediate impact of this training on participant", and eighth was 
on "What was learnt in training, how participant will apply in her practice".

The informed consent was taken from the participants and ethical approval was obtained from institutional review committee of UCMS.

The data collected was checked for completeness, accuracy and consistency. It was entered in IBM SPSS version 21 for analysis. Descriptive analysis was done; the frequency, mean and standard deviation were computed.

\section{Results}

The findings are presented based on the parts of questionnaire: Part A. Demographic information, Part B. Overall feedback on training workshop, Part C. Feedback on specific group of sessions and Part D. Feedback on strengths, areas for improvement, immediate impact and application in practice.

\section{Part A}

\section{Demographic information}

The mean age of the participants was $35.13 \pm 9.81$ years (range 27-65 years); all were females. The mean experience teaching undergraduate students was $4.93 \pm 3.57$ years (range 0-14) while mean experience teaching postgraduate students was $1.07 \pm 1.47$ years (range 0-5). Their year of graduation was between 1996-2015 while post-graduation 2009-2019. None of the participants received any ethics related training before.

\section{Part B}

\section{Overall feedback on training workshop}

The participant nursing faculty members rated training on scale of $1-10(1=$ poor, $10=$ excellent $)$; their rating was notable. (Table 1 )

Table 1: Rating of the participant nursing faculty members on "Training to train nursing teachers helping nursing students learn ethics"

\begin{tabular}{|l|l|c|}
\hline S. No & \multicolumn{1}{|c|}{ Item } & Rating (Mean \pm SD) \\
\hline 1a. & Usefulness (Scale 1-10) & $7.33 \pm 1.17$ \\
\hline 1b. & Content (Scale 1-10) & $7.40 \pm 1.06$ \\
\hline 1c. & Relevance of session \& content (Scale 1-10) & $7.93 \pm 0.70$ \\
\hline 1d. & Facilitation (Scale 1-10) & $7.67 \pm 0.98$ \\
\hline 1e. & Overall (Scale 1-10) & $7.93 \pm 0.70$ \\
\hline
\end{tabular}

\section{Part C}

Feedback on specific group of sessions

The rating of the participant nursing faculty members on their confidence level after participating in training was also remarkable.

Table 2: Rating of the participant nursing faculty members on specific session of "Training to train nursing teachers helping nursing students learn ethics"

\begin{tabular}{|l|l|c|}
\hline S. No & \multicolumn{1}{|c|}{ Item } & Rating (Mean \pm SD) \\
\hline 2 & $\begin{array}{l}\text { Confident to conduct and facilitate "Think, Pair and Share" } \\
\text { interactive session for teaching nursing ethics to students? } \\
*(\text { Likert scale 1-4) }\end{array}$ & $3.47 \pm 0.52$ \\
\hline 3 & $\begin{array}{l}\text { Confident to conduct and facilitate "Scenario-based Group } \\
\text { Work Discussion" session for teaching nursing ethics to } \\
\text { students? on *Likert scale 1-4 }\end{array}$ & $3.60 \pm 0.50$ \\
\hline 4 & $\begin{array}{l}\text { Importance of "Teaching Nursing Clinical Ethics" session } \\
\text { on **Likert scale 1-4 }\end{array}$ & $3.80 \pm 0.41$ \\
\hline
\end{tabular}

*(4= highly confident, $3=$ very confident, $2=$ confident, $1=$ not confident);

**(4= extremely important, $3=$ moderately important, $2=$ slightly important, $1=$ not important $)$

\section{Part D}

Feedback on strengths, areas for improvement, overall immediate impact and application in practice

Good points/strengths
Good points/strengths of training shared by the participants were: conducive and friendly environment; very interactive, useful content/topics; scenario-based group work discussion; Think, Pair and Share session; how to teach ethics to students; ethical issues; application of ethical principles; participatory training, 
resourceful resource person and relevant examples and scenario.

\section{Areas for improvement}

The suggested areas for improvement shared by the participants were: include more scenario-based group work discussion; conduct pre and posttest to assess the knowledge level of teachers and further improvement; include more examples of ethical issues and dilemmas; increase credit hours for training; share more real examples; involve nursing resource persons too.

\section{Overall immediate impact}

Immediate impact perceived by the participants was: committed for what was learnt will apply for teaching ethics to nursing students and in clinical nursing practice too and will sensitize nursing students about importance of ethics and its application besides teaching subjects, become more confident and motivated about the topics and criteria to be followed in teaching ethics; enabled to identify the problembased ethical issues and resolve ethical dilemma/s; internalized spark for ethical teaching.

\section{Application in practice}

Participants mentioned that from new academic session they will develop ethics code of Universal College of Nursing Sciences (UCNS) and form ethical committee to resolve ethical problems faced by students; create scenarios; help nursing students to apply ethical principles; apply ethical principles in each and every area of practice; make decision based on ethical principles.

\section{Discussion}

Ethical/legal principles and professionalism are among the core competencies of the nurse educator defined by World Health Organizations (WHO). (8) Educators or teachers are among the significant and main components for developing ethical competence of nursing students. (7) The clinical nursing trainers are the key persons who can convert principles of professional ethics from theory to practice and teach it to the students. (5) Therefore, UCMS organized training for clinical nursing trainers to sensitize them "why to teach ethics to nursing students" and prepare them "helping nursing students learn nursing ethics" The present study assessed feedback of the participant nursing faculty members; the feedbackhelps in updating the content and methodology of training, improve delivery of content and organization of training too.

The rating of participants on training was noteworthy for usefulness, content, relevance facilitation and overall. Their confidence to conduct and facilitate "Think-Pair-Share" interactive session and "Scenariobased Group-Work Discussion"enhanced as perceived by them. Participants rating on Teaching clinical nursing ethics session was also remarkable. Conducive and friendly environment, very interactive sessions, useful content/topics, scenario-based group work discussion and Think, Pair and Share interactive session were some of the strengths of training shared by the participants. They suggested to include more scenario-based group work discussion, conduct pre and posttest to assess improvement in the knowledge level of teachers, include more examples of ethical issues and dilemmas and increase credit hours for training. Participants committed for what was learnt will apply for teaching ethics to nursing students and in clinical nursing practice too. Participants also reported that they will develop ethics code for their institution and form ethical committee to resolve ethical problem faced by students.

The findings of present study are consistent with the feedback on short-duration ethics training programs for teachers conducted by Ramana K V et al (2013), Ramalingam $S$ et al (2014) and Ajuwon Ademola J et al (2008). [9, 19, 11]

The limitations of present study are small sample size and conducted in one institute, hence, the findings cannot be generalized. But overall perception of the participants was positive regarding training; training enhanced their confidence level and increased their commitment regarding teaching ethics to students and its application in practice.

\section{Acknowledgement}

We appreciate nursing faculty members of various departments of Universal College of Nursing Sciences of Universal College of Medical Sciences, Bhairahawa, Nepal for their voluntary participation in this study.

\section{References}

1. Buelow JR, Mahan PL, Garrity AW. Ethical Dilemmas as Perceived by Healthcare Students with Teaching Implications. Journal of College Teaching \& Learning 2010; 7 (2): 85-92.

2. Buxton M, Phillippi JC, Collins M R. Simulation: A New Approach to Teaching 
Ethics. Journal of Midwifery \& Women's Health 2014; 00 (0): 1-5.

3. Bahrieni F, Azodi P, Hajivandi A, Jahanpour. The Effect of Education in Nurse's Moral Sensitivity. J. Pharm. Sci. \& Res 2017; 9 (10): 1817-1821.

4. Borhani F, Alhani F, Mohammadi E, Abbaszadeh A, Mirzaee M, Farokhzadian J. The importance of professional values from nursing students' perspective. BMC Nursing 2019; 18 (26):2-7.

5. Dashti S, Shahmari M. Comparison of professional ethics score between nurses and students and investigating the associated causes. Bali Medical Journal 2017; 6 (3): 668-673.

6. Jahanpour F, Sharif F, Salsali M, Kaveh MH, Williams LM. Clinical decision-making in senior nursing students in Iran. International journal of nursing practice. 2010; 16(6):595-602.

7. Borhani F, Alhani F, Mohammadi E, Abbaszadeh A. Professional Ethical Competence in nursing: the role of nursing instructors. J Med Ethics Hist Med 2010; 3 (3):1-8..

8. Nurse educator core competencies. World Health Organization 2016

https://www.who.int/hrh/nursing_midwifery/nurs e_educator050416.pdf.

Accessed on December 11, 2019.

9. Ramana K V, Kandi S, Boinpally PR. Ethics in medical education, practice, and research: An insight. Ann Trop Med Public Health 2013; 6: 599-602.

10. Ramalingam S, Bhuvaneswar S i, SanKaRan R. Ethics workshops-are they effective in improving the competencies of faculty and postgraduates? Journal of clinical and diagnostic research: JCDR 2014; 8 (7), XC01. DOI:

11. Ajuwon Ademola J, Kass Nancy, Outcome of a research ethics training workshop among clinicians and scientists in a Nigerian university BMC Medical Ethics 2008; 9 (1): 9-1.

\section{Source of Support: Nil}

Conflict of Interest: Nil 